\title{
Scire Science Multidisciplinary Journal
}

Scire Science Multidisciplinary Journal 1(1),2017

An Open Access, Online International Journal Available at http://www.scire.co.in/journal.php

2017, Sanjana et al.

DOI:https://doi.org/10.25129/SSMJRA2017.156

\section{Research Article}

\section{Path towards genetic diversity analysis and evaluation of blast resistant} genes in popular varieties of paddy

\section{${ }^{1}$ Sanjana.N.* ${ }^{2}$ Manisha Basu, ${ }^{3}$ Manoj Kumar H ${ }^{4}$ and Harini Kumar KM}

${ }^{1,2}$ Department of Biotechnology, Ramaiah Institute of Technology, Bengaluru-560054, India.

${ }^{3,4}$ Department of Plant Biotechnology, University of Agricultural Sciences, GKVK,

Bengaluru-560065, India.

*Corresponding author: sanjananarendar@gmail.com

Accepted: July 2017, Available online: 27 September 2017

Objective: DNA isolation and quantification of selected rice varieties. Identification of blast resistance genes in rice varieties through genotypic method. Diversity analysis for rice varieties through set of SSR markers

Methodology:

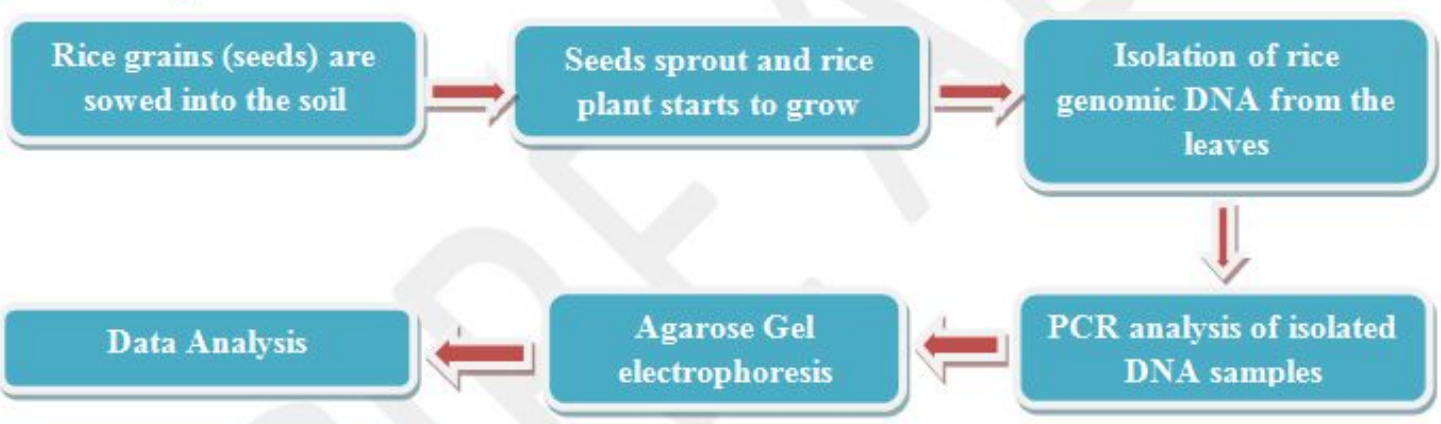

Duration taken for the research: 3 months

Conclusion: A total of 44 alleles, an average PIC value of 0.41 and cluster analysis performed by using UPGMA resolved 19 advanced breeding lines into two major clusters with $24 \%$ dissimilarity so the set of markers used were highly informative and useful for genetic diversity studies as well as most of the lines might have maximum number of shared genetic loci which reflects the closeness.

Applicable Industries: Agriculture and Horticulture

Applicable geographical area: Kamataka, India

Expected outcome: The major difficulty in controlling rice blast is the durability of genetic resistance so enhancing the host plant resistance, intemational cooperation, completion of the rice genome project and candidate gene identification through rice functional genomics are the best approaches for handling the rice blast disease. 
Scire Science Multidisciplinary Journal, 1(1), 15-26 (2017)

\title{
Research Article \\ Path towards genetic diversity analysis and evaluation of blast resistant genes in popular varieties of paddy
}

Sanjana et al.

\begin{abstract}
Rice being one of the most important cereal crops holds the second prominent position in global agriculture.With everyday increase in population, adverse climatic changes and new pathogen and pest activities, the rice breeders are facing great challenges to meet the demands. Worldwide rice is affected by most devastating blast disease caused by Magnaporthe grisea. Although chemical control is often found to be successful, this adds to the cost of cultivation and also contaminates the environment. To address this problem the genetic diversity analysis and evaluation of blast resistant genes in rice with the help of SSR molecular markers was conducted. The use of rice genetic resources available at the Rice Research Laboratory can be used to incorporate the genetic variability in rice breeding programme. This will allow new cultivars with broadened genetic basis to create new and useful allelic combination. Development of crosses can be used to broaden the genetic basis of rice and promote the preservation of rare alleles which can be incorporated into elite germplasm. Domestication of crops restricts the crop improvement by limiting the range of valuable traits used in modern plant breeding. The assessment of genetic diversity allows germplasm characterization and conservation. Wild species can improve germplasm but create problems due to reproductive isolation. Rice crop suffers from yield plateau due to narrow genetic base as well. Genetic variability is used in crop improvement program .In this present study 19 advanced breeding lines were selected for diversity analysis among rice varieties.
\end{abstract}

Keywords: Blast disease, Genetic diversity analysis, Magnaporthe grisea, SSR (simple sequence repeat) molecular markers.

\section{Introduction}

Various pathogens such as viruses, nematodes, bacteria, fungi and insects attack plants. Resistance (R) genes present in plant identifies the Avirulence (Avr) genes in insects and thus protect the plants from these attacks. Rice blast caused by the fungi Magnaporthe grisea is one of the most devastating diseases occurring in rice plant (Ashikawa et al., 2008).Cloning of blast resistance genes, fine mapping techniqueswith aid of PCR-based markers help in identifying different blast resistance genes. Marker assisted selection (MAS) can be effectively employed when DNA markers are closely linked to blast $\mathrm{R}$ gene, conferring resistance towards a particular variety of paddy against the blast disease. Recently more than 100 blast resistant genes are identified from aponica (45\%), indica (51\%) and other (4\%) genotypes and many of them have been cloned. It is expected that MAS of blast resistant genes shall help breeding programmers by the production of multi-disease resistant rice. Even though MAS has an advantage of identifying resistance, the main power depends on the markers used. PCR- 
Scire Science Multidisciplinary Journal, 1(1), 15-26 (2017)

\section{Research Article \\ Path towards genetic diversity analysis and evaluation of blast resistant genes in popular varieties of paddy}

Sanjana et al.

based markers and SSR molecular markers are effective in screening of resistance genes (Rau et al., 2000). Pi-ta and Pi-ta2 genes identified by Kiyosawa and colleagues have been found to be tightly linked to the centromere on chromosome 12 which are linked to cluster of R genes. AVR-Pita is avirulent alleles of Magnaporthe grisea. The development of $\mathrm{R}$ genes for effectively controlling genetically occurring rice blast disease was aided by cloning the AVR-Pita and Pi-ta genes (Bryan et al., 2000).

\section{Materials and methods}

This project was carried out during 2017 at the Dept of Plant biotechnology, University Agricultural Sciences, GKVK, and Bangalore, India. The experimental material for this investigation comprised of 19 genotypes and a total of four simple sequence repeat (SSR) markers, i.e., 30 markers were used for studying molecular diversity (Table 1 and Table 2).

\section{Isolation of rice genomic DNA Sample Preparation}

Already collected and stored tender, fully expanded leaves (20-25 days old) were initially surface sterilized with ethanol (70\%) before extraction.

\section{Extraction of genomic DNA}

Two gram of leaf samples were cut frozen using liquid nitrogen and ground into a fine powder in a pre chilled mortar. The fine powder was thawed in $1.5 \mathrm{ml}$ of pre-heated extraction buffer (CTABCetyl Trimethyl Ammonium Bromide) in $2 \mathrm{ml}$ of polypropylene centrifuge tubes and incubated for 30 minutes at $65^{\circ} \mathrm{C}$ in water bath with occasional mixing. Following this equal volume of chloroform isoamylalcohol mixture was added and mixed by inversion for 15 minutes and centrifuged at 10,000 rpm for 20 minutes at room temperature. The clear aqueous phase was transferred to a new sterile tube to which equal volume of ice cold isopropanol was added and mixed gently by inversion and then kept in the $-20{ }^{\circ} \mathrm{C}$ freezer to precipitate DNA for whole night. The tubes were then centrifuged at 8000 rpm for 20 minutes and sedimentation of DNA as a hard pellet was seen. The pellet was washed twice by suspending in $1 \mathrm{~mL}$ of 70 percent ethanol for 5 to 10 minutes and the DNA was centrifuged at $6000 \mathrm{rpm}$ for five minutes. Ethanol was drained off slowly and the pellet was air dried then dissolved in $100 \mu \mathrm{l}$ of TE buffer by flicking the tubes. (Sterile $\mathrm{H}_{2} \mathrm{O} /$ TEbuffer $=0.1 \mathrm{mM}$ Tris +0.05 $\mathrm{mM}$ EDTA) and stored at $-20^{\circ} \mathrm{C}$. The extracted DNA was subjected for checking quality and quantification using both Biospec-nano and by 0.8 per cent agarose gel electrophoresis. 
Scire Science Multidisciplinary Journal, 1(1), 15-26 (2017)

Research Article

Path towards genetic diversity analysis and evaluation of blast resistant genes in popular varieties of paddy

Sanjana et al.

Table 1: Improved Varieties of rice selected to identify the blast resistant genes at molecular level and genetic diversity analysis

\begin{tabular}{|c|c|c|c|}
\hline CODING NO. & $\underline{\text { SAMPLE'S NAME }}$ & $\underline{\text { CODING NO. }}$ & $\underline{\text { SAMPLE'S NAME }}$ \\
\hline 1 & IR64 & 11 & JAYA \\
\hline 2 & MTU1001 & 12 & THANU \\
\hline 3 & GSONA & 13 & RASI \\
\hline 4 & RAJMUDI & 14 & JAYACROSS \\
\hline 5 & RATNACHOODI & 15 & MSONA \\
\hline 6 & BR2655 & 16 & ANAGHA \\
\hline 7 & BPT & 17 & IET30864 \\
\hline 8 & MTU1010 & 18 & \\
\hline 9 & KMP175 & 19 & \\
\hline 10 & KMP153 & & \\
\hline
\end{tabular}

\section{DNA purity and quantification done by nano spectrophotometer}

To estimate the DNA purity advanced automated DNA quantifier Biospec-nano was used and ratios between $260 \mathrm{~nm}$ and $280 \mathrm{~nm}$ was estimated. Pure DNA samples will have a ratio of 1.8 to 2.0. If the sample is contaminated by protein the ratio will be significantly less than 1.8. Ratio of 2.0 or more indicates a high proportion of RNA in the sample. With this informationpure DNA was prepared (ratios of 1.8 to 2.0) and further dilution was decided. All the samples were diluted to a final concentration of $40 \mathrm{ng} / \mu \mathrm{l}$. Loading dye consisted of Glycerol $50 \%(\mathrm{~V} / \mathrm{V})$; Bromophenol blue $0.5 \%$ $(\mathrm{W} / \mathrm{V})$ and 10X TBE (Tris Boric EDTA buffer) .Volume was made up to $1000 \mathrm{ml}$ with $8.0 \mathrm{pH}$. Agarose $0.8 \%(0.8 \mathrm{~g} / 100 \mathrm{ml})$ was added to $1 \mathrm{x}$ TBE, boiled until the agarose dissolved completely and then allowed to cool. Ethidium bromide $(5 \mu \mathrm{l} / 100 \mathrm{ml})$ was added to fluorescence the DNA under UV light. Then it was poured into the gel mould and allowed to solidify. The gel was placed in the electrophoresis unit with wells towards the cathode and submerged with 1XTBE to a depth of about $1 \mathrm{~cm}$. About $2 \mu \mathrm{l}$ of the DNA sample mixed with $2 \mu \mathrm{l}$ of loading dye was loaded. The electrophoresis was carried out at $100 \mathrm{~V}$ for $10-15 \mathrm{~min}$. Bands were visualized and documented using a gel documentation system (Gene flash). 
Scire Science Multidisciplinary Journal, 1(1), 15-26 (2017)

Research Article

Path towards genetic diversity analysis and evaluation of blast resistant genes in popular varieties of paddy

Sanjana et al.

Table 2: Finalized Polymorphic Markers for identification of blast resistant genes

\begin{tabular}{|c|c|c|c|c|c|c|}
\hline$\underline{\text { Sl. }}$ & Marker & Gene & Forward primer & $\underline{\text { Reverse primer }}$ & $\begin{array}{l}\frac{\text { Res. }}{\text { Allel }} \\
\underline{\text { e }} \\
\text { Size } \\
\end{array}$ & $\underline{\text { References }}$ \\
\hline 1 & RM3825 & Pish & AAAGCCCCCAAAAGCAGTAC & GTGAAACTCTGGGGTGTTCG & 230 & $\begin{array}{l}\text { Berruyer } \text { et al., } \\
2003\end{array}$ \\
\hline 2 & RM72 & $P i-33$ & CCGGCGATAAAACAATGAG & GCATCGGTCCTAACTAAGGG & 290 & $\begin{array}{l}\text { Wang et al., } \\
2009 .\end{array}$ \\
\hline 3 & RM1896 & $\begin{array}{l}P i i, P i 3(t), \\
P i-5(t)\end{array}$ & GGACAGGGTAAAGTGTTAGA & CCTAAGACCTATCAACTCCA & 168 & $\begin{array}{l}\text { Sharma et al. } \\
2002\end{array}$ \\
\hline 4 & RM206 & $P i-38$ & CCCATGCGTTTAACTATTCT & CGTTCCATCGATCCGTATGG & 256 & $\begin{array}{l}\text { Fjellstrom et } \\
\text { al. } 2004\end{array}$ \\
\hline & RM224 & $P i k$ & ATCGATCGATCTTCACGAGG & TGCTATAAAAGGCATTCGGG & 291 & Li et al. 2008 \\
\hline 6 & $\begin{array}{l}\text { Pi54 } \\
\text { Indel }\end{array}$ & Pi54 & CAATCTCCAAAGTTTTCAGG & GCTTCAATCACTGCTAGACC & 210 & $\begin{array}{l}\text { Hayashi et al., } \\
2006\end{array}$ \\
\hline 7 & Nmsm & $P i 9$ & CGAGAAGGACATCTGGTACG & GAGATGCTTGGATTTAGAAGAC & 290 & $\begin{array}{l}\text { Fjellstrom et } \\
\text { al. } 2004\end{array}$ \\
\hline 8 & $\begin{array}{l}\text { AP5659- } \\
5\end{array}$ & $\mathrm{Pi2} / \mathrm{Piz}$ & СТCСTTCAGCTGCTCCTC & TGATGACTTCCAAACGGTAG & 310 & Li et al. 2008 \\
\hline
\end{tabular}

\section{$\underline{\text { PCR analysis }}$}

Thirty microsatellites were used to easily amplify by the PCR (Polymerase Chain reaction) using unique flanking sequences as forward and reverse primers. The reaction mixture was given a momentary spin for thorough mixing of the cocktail components. Then $0.20 \mathrm{ml}$ PCR tubes were loaded in a thermal cycler (Table 3 and Table 4). 
Scire Science Multidisciplinary Journal, 1(1), 15-26 (2017)

\section{Research Article}

Path towards genetic diversity analysis and evaluation of blast resistant genes in popular varieties of paddy

Sanjana et al.

Table 3: PCR components

\section{PCR components}

\begin{tabular}{|l|l|l|}
\hline PCR components & Concentration & Quantity \\
\hline Primers & & \\
\hline Forward & $10 \mu \mathrm{M}$ & $1.0 \mu \mathrm{l}$ \\
\hline Reverse & $10 \mu \mathrm{M}$ & $1.0 \mu \mathrm{l}$ \\
\hline Template DNA & $40 \mathrm{ng} / \mu \mathrm{l}$ & $1.0 \mu \mathrm{l}$ \\
\hline Sterile water & & $6.1 \mu \mathrm{l}$ \\
\hline Taq pol & $3 \mathrm{u}$ & $0.1 \mu \mathrm{l}$ \\
\hline DNTps & $2.5 \mathrm{mM}$ & $0.8 \mu \mathrm{l}$ \\
\hline Total & & $10 \mu \mathrm{l}$ \\
\hline
\end{tabular}

Table 4: Temperature profile used for PCR amplification using SSR primers

Temperature profile used for PCR amplification using SSR primers

\begin{tabular}{|c|l|c|l|c|}
\hline Profile & \multicolumn{1}{|c|}{ Activity } & $\begin{array}{c}\text { Temperature } \\
\left({ }^{\circ} \mathrm{C}\right)\end{array}$ & Duration & Cycles \\
\hline 1. & Initial denaturation & 95 & 5 mins & 1 \\
2. & Denaturation & 95 & 30 secs & \\
3. & Annealing & 55 & 30 secs & 34 \\
4. & Extension & 72 & 1 mins & 1 \\
5. & Final extension & 72 & 10 mins & 1 \\
6. & Storage & 4 & $\infty$ & \\
\hline
\end{tabular}

\section{Data analysis}

The amplified fragments were scored as absence (0) or presence (1) of amplicon linked to each blast resistance gene DNA fragment. Using Jaccard's coefficient, genetic similarities were analyzed from the binary data matrix (Sneath and Sokal, 1973). The similarity coefficient was used for cluster 
Scire Science Multidisciplinary Journal, 1(1), 15-26 (2017)

\section{Research Article \\ Path towards genetic diversity analysis and evaluation of blast resistant genes in popular varieties of paddy}

Sanjana et al.

analysis of traditional rice varieties utilizing UPGMA (unweighted pair group method with arithmetic averages).

\section{Results and discussion}

Rice crop suffers from yield plateau because of narrow genetic base. To overcome plateau, there is a need to broaden the genetic base or select the diverse set of lines in the breeding populations. The variety Samba mahsuri is extremely popular among rice farmers and consumers because of its high yield, medium-slender, fine grain type and excellent cooking and eating quality. This variety is being targeted for improvement of multiple traits like biotic and abiotic stress tolerance or resistance. Creation of genetic variability is a pre-requisite for any crop improvement program. Keeping these points in view, in present study 19 advanced breeding lines which were selected and diversity analysis was carried out among those to determine the diversity (Figure 1).

\section{Molecular markers analysis}

\section{Number of alleles}

In present study, a total of 44 alleles were detected across 19 advanced breeding lines of rice. The numbers of alleles generated per locus by each marker were ranged from 2 to 3 . This was comparable to the report of Prabakaran et al., 2010 for genetic divergence of rice land races where in they reported average alleles of 2.2 per locus The results obtained in present study were lower than the observations made by (Li et al., 2012, Rabey et al., 2013) average number of alleles detected were 3.5, 3.83 and 2.75 in Taiwan rice germplasms, genetic diversity of eight rice cultivars, diversity within the aromatic and non-aromatic rice varieties respectively. However, in the present study, less number of alleles was detected since the works was carried among the advanced breeding lines of the same region, where the variations are expected in the small regions of the genome as generally due to lesser recombination.

\section{Polymorphism of SSR markers}

In present study, a total of 30 SSR markers (approx 2 to 3 markers per chromosomes) were selected to assess the extent of genetic diversity across 19 advanced breeding lines of rice. Of 30 SSR markers, 8 were found to be polymorphic and remaining 3 were not amplified and rests were monomorphic.

\section{Polymorphism information content (PIC) values}

Polymorphism Information Content (PIC) value is the reflection of allelic diversity and frequency among the varieties or lines. To measure the in formativeness of each SSR marker, PIC values were calculated. In the present study, PIC values varied widely among SSR loci tested and it ranged from 
Scire Science Multidisciplinary Journal, 1(1), 15-26 (2017)

\section{Research Article \\ Path towards genetic diversity analysis and evaluation of blast resistant genes in popular varieties of paddy}

Sanjana et al. 0.36 (RM 1007 chromosome 1) to 0.48 (RM 24914 of chromosome 10), with an average of 0.41 per marker.In the present study, the hyper variable SSR markers was selected which covered uniformly across the genome, hence resulted a fair amount of PIC values for these markers. Among polymorphic SSR markers, RM 26213 of chromosome 11 (with repeat motive of (TA) 46) showed maximum number of alleles 3 as well as high PIC value 0.816. Markers with PIC values of 0.5 or above are highly informative for genetic studies since they are extremely useful in distinguishing the polymorphism rate of a specific locus (DeWoody et al., 1995; Akkaya and Buyukunal Bal, 2004).Hence in present study, set of markers showed an average PIC value 0.41 , hence these could considered as highly informative and useful for genetic diversity studies.

Genetic diversity pattern by cluster analysis (cluster analysis performed by using UPGMA based on similarity co-efficient values).

It resolved 19 advanced breeding lines into two major clusters with $24 \%$ dissimilarity. While cluster-I was major cluster with 18 lines and it was divided into two sub clusters i.e. IA and IB and they showed $25 \%$ dissimilarity. Cluster II consisted of only one breeding line i.e. MTU 1001. Cluster IA was a major sub cluster which had 16 lines, where as sub cluster IB consisted of two breeding line. For clarity, again divided the Cluster- IA in to two sub clusters viz I-AB and I-AC and they showed $14 \%$ dissimilarity. The sub cluster I-AB comprised of 14 lines where as I-AC comprised of 2 lines only. This analysis revealed that most of the lines might have maximum number of shared genetic loci. Upadhyay et al., (2011) reported clustering of 29 rice genotypes in to major clusters while studying the development of molecular tags for rice lines. Rajendran et al., 2013 studied clustering of maintainer and restorer groups into two different clusters in DNA fingerprinting and estimation of genetic diversity among hybrid rice parental lines (Oryza sativa L.). This showed that the diversity pattern observed among 19 advanced breeding lines in the present study based on cluster analysis using UPGMA software reflects the closeness (Figure 2 and Table 5).

\section{Conclusion}

Rice an important cereal crop has is diploid $(2 n=24)$ and has a relatively small genome $(430 \mathrm{Mb})$. Rice productivity is adversely impacted by Blast disease of rice caused by Magnaporthe grisea. The fungus attacks aerial parts of the rice plant at any stage of plant growth through the production of lesions on the leaves, nodes and panicles. Although chemical control is successful, it adds to the cost of cultivation and also contaminates the environment. Molecular markers used to point the position of a particular gene or the inheritance of a particular trait. In this project of four simple sequences repeat SSR (Simple sequence repeats), i.e., 30 markers were used.DNA of total 19 rice varieties were 
Research Article

Path towards genetic diversity analysis and evaluation of blast resistant genes in popular

varieties of paddy

Sanjana et al.

extracted from the frozen leaf sample. The extracted DNA was subjected for checking quality and quantification using both Biospec-nano and by 0.8 per cent agarose gel electrophoresis.

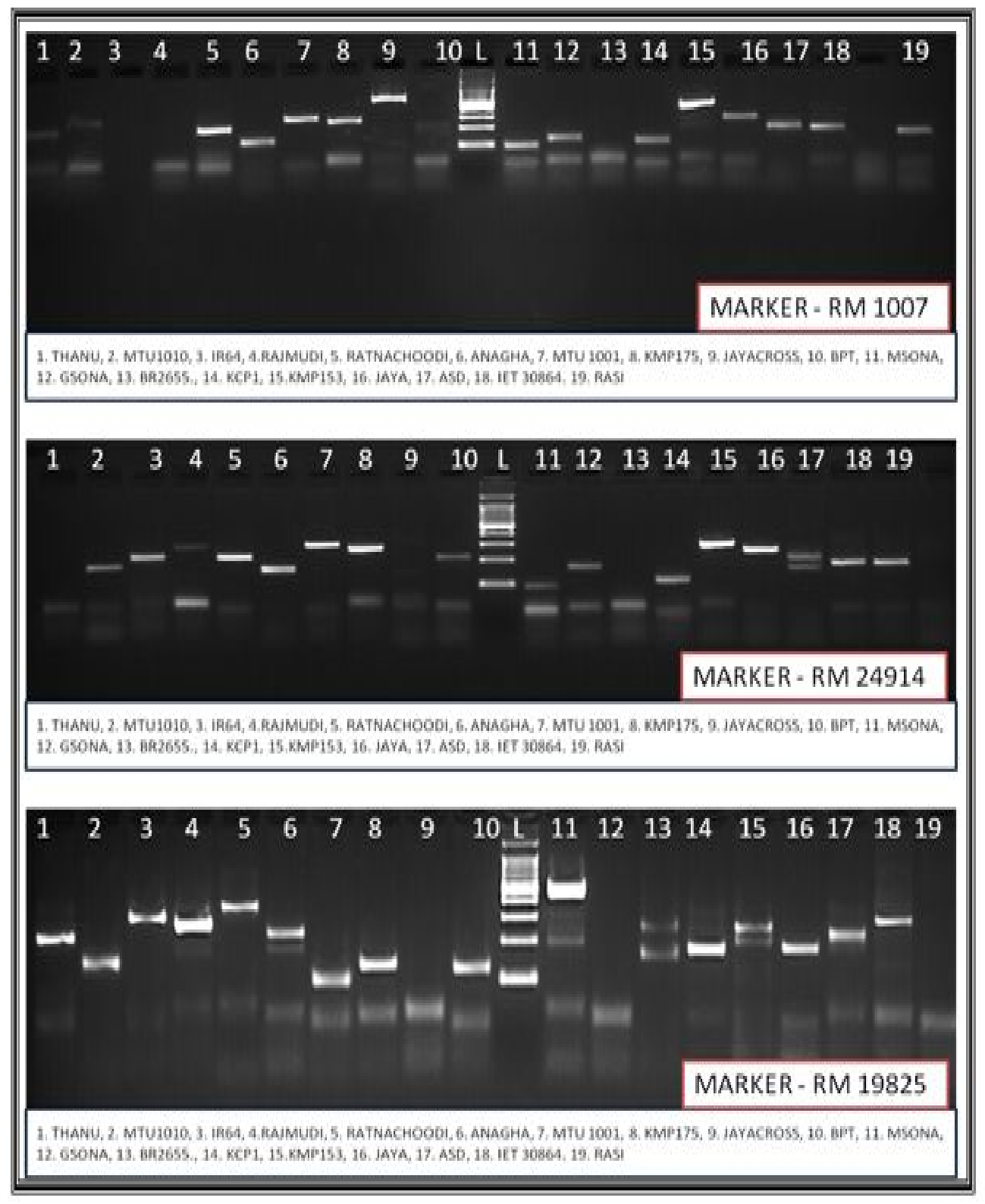

Figure 1: Gel profiles of different markers used in this study 
Scire Science Multidisciplinary Journal, 1(1), 15-26 (2017)

Research Article

Path towards genetic diversity analysis and evaluation of blast resistant genes in popular varieties of paddy

Sanjana et al.

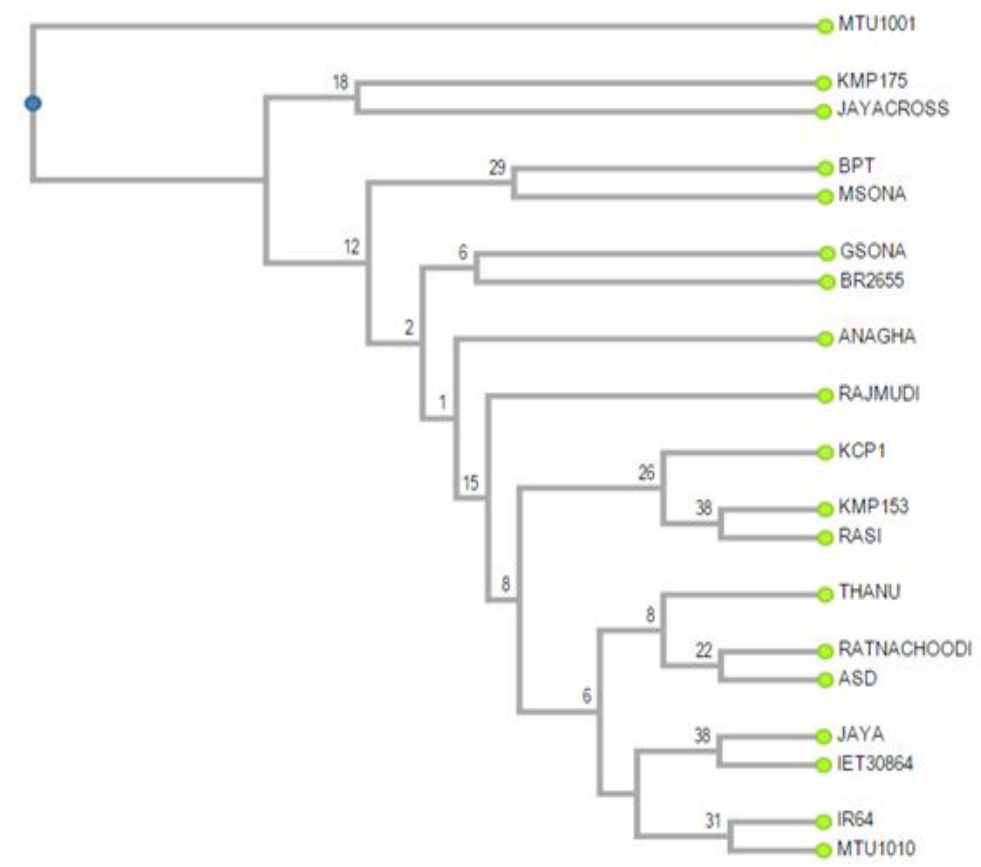

Figure 2: Genetic diversity analysis through UPGMA software

Table 5: Similarity matrix computed with Jaccard's coefficient

\begin{tabular}{|c|c|c|c|c|c|c|c|c|c|c|c|c|c|c|c|c|c|c|c|}
\hline & \begin{tabular}{|l|l|} 
IR64 \\
\end{tabular} & MTU1001 & GSONA & RAMMUDI & RATTNACHOOOI & BR2655 & BPT & MTU11010 & KMP175 & KMP153 & \begin{tabular}{|l|l} 
JaYA & -1 \\
\end{tabular} & Thanu & RASI & JaYACROSS & Aso & MSONA & ANAGHa & KCP1 & |EJ30654 \\
\hline |R64 & 1 & 0.2 & 0.7 & 0.7 & 0.8 & 0.6 & 0.4 & 0.9 & 0.4 & 0.8 & 0.9 & 0.7 & 0.9 & 0.5 & 0.9 & 0.6 & 0.7 & 0.7 & 0.8 \\
\hline MTU1001 & & 1 & 0.125 & 0.286 & 0.25 & 0.143 & 0 & 0.222 & 0 & 0.111 & 0.222 & 0.286 & 0.1 & \begin{tabular}{|l|}
0.167 \\
\end{tabular} & 0.222 & 0 & 0 & 0.125 & 0.25 \\
\hline GSONA & & & 1 & 0.556 & \begin{tabular}{|l|l|}
0.667 \\
\end{tabular} & 0.625 & 0.375 & 0.6 & 0.222 & 0.5 & 0.6 & \begin{tabular}{|l|}
0.556 \\
\end{tabular} & 0.6 & \begin{tabular}{|l|l|}
0.333 \\
\end{tabular} & \begin{tabular}{|l|l|} 
& 0.778 \\
\end{tabular} & \begin{tabular}{|l|}
0.625 \\
\end{tabular} & 0.556 & 0.4 & 0.667 \\
\hline RANMUDI & & & & 1 & 0.667 & 0.625 & 0.375 & 0.6 & 0.222 & 0.667 & 0.6 & \begin{tabular}{|l|l|}
0.556 \\
\end{tabular} & 0.6 & 0.5 & 0.778 & \begin{tabular}{|l|l|} 
\\
\end{tabular} & 0.4 & 0.556 & 0.667 \\
\hline RATNACHOOOO & & & & & 1 & 0.556 & 0.5 & 0.7 & 0.333 & 0.6 & 0.7 & 0.875 & 0.7 & 0.444 & 0.889 & 0.75 & 0.5 & 0.667 & 0.778 \\
\hline BR2655 & & & & & & 1 & $\begin{array}{l}0.25 \\
\end{array}$ & 0.667 & 0.429 & 0.4 & 0.5 & \begin{tabular}{|l|l|}
0.625 \\
\end{tabular} & 0.5 & 0.571 & 0.667 & 0.5 & 0.444 & 0.3 & 0.556 \\
\hline BPT & & & & & & & 1 & 0.3 & 0.333 & 0.5 & 0.444 & 0.375 & 0.44 & \begin{tabular}{|l}
0.286 \\
\end{tabular} & 0.44 & \begin{tabular}{|l|}
0.667 \\
\end{tabular} & 0.571 & 0.571 & 0.5 \\
\hline MTV1010 & & & & & & & & 1 & 0.444 & 0.7 & 0.8 & \begin{tabular}{|l|}
0.778 \\
\end{tabular} & 0.8 & 0.556 & 0.8 & 0.5 & 0.6 & 0.6 & 0.7 \\
\hline KMP175 & & & & & & & & & 1 & 0.333 & 0.44 & 0.375 & 0.44 & 0.5 & 0.3 & 0.429 & 0.571 & 0.375 & 0.333 \\
\hline KMP153 & & & & & & & & & & 1 & 0.7 & 0.5 & 0.889 & 0.444 & 0.7 & \begin{tabular}{|l|}
0.556 \\
\end{tabular} & 0.667 & 0.875 & 0.6 \\
\hline JaYA & & & & & & & & & & & 1 & 0.6 & 0.8 & 0.4 & 0.8 & 0.5 & 0.778 & 0.6 & 0.889 \\
\hline THANU & & & & & & & & & & & & 1 & 0.6 & 0.5 & 0.778 & \begin{tabular}{|l|l|}
0.625 \\
\end{tabular} & 0.4 & 0.556 & 0.667 \\
\hline RASI & & & & & & & & & & & & & 1 & 0.4 & 0.8 & \begin{tabular}{|l|l|}
0.667 \\
\end{tabular} & 0.778 & 0.778 & 0.7 \\
\hline Jayacrosss & & & & & & & & & & & & & & 1 & 0.4 & 0.375 & 0.333 & 0.5 & 0.3 \\
\hline ASD & & & & & & & & & & & & & & & 1 & \begin{tabular}{|l|}
0.667 \\
\end{tabular} & 0.6 & 0.6 & 0.889 \\
\hline MSONA & & & & & & & & & & & & & & & & 1 & 0.625 & 0.625 & 0.556 \\
\hline ANAGHA & & & & & & & & & & & & & & & & & 1 & 0.556 & 0.667 \\
\hline KCP1 & & & & & & & & & & & & & & & & & & 1 & 0.5 \\
\hline |ET30864 & & & & & & & & & & & & & & & & & & & 1 \\
\hline
\end{tabular}


Scire Science Multidisciplinary Journal, 1(1), 15-26 (2017)

\section{Research Article \\ Path towards genetic diversity analysis and evaluation of blast resistant genes in popular varieties of paddy}

Then thirty microsatellites were used to easily amplify by the PCR (Polymerase Chain reaction) using unique flanking sequences as forward and reverse primers. The Resolution of amplified products on agarose gel electrophoresis was done. Using Jaccard's coefficient, genetic similarities were analyzed from the binary data matrix (Sneath and Sokal, 1973).The similarity coefficient was used for cluster analysis of traditional rice varieties utilizing UPGMA. Of 30 SSR markers, 8 were found to be polymorphic and remaining 3 were not amplified and rests were monomorphic. In present study, a total of 44 alleles were detected across 19 advanced breeding lines of rice and set of markers showed an average PIC value 0.41 , hence these could considered as highly informative and useful for genetic diversity studies. Genetic diversity pattern, cluster analysis performed by using UPGMA based on similarity co-efficient values resolved 19 advanced breeding lines into two major clusters with $24 \%$ dissimilarity and this analysis revealed that most of the lines might have maximum number of shared genetic loci which reflects the closeness.

\section{Social relevance, expected outcome and limitations}

During the evolution and artificial selection processes a significant portion of beneficial alleles was left behind in the landraces which could have been used for the development of better rice varieties. The major difficulty in controlling rice blast is the durability of genetic resistance so enhancing the host plant resistance, international cooperation, completion of the rice genome project and candidate gene identification through rice functional genomics are the best approaches for handling the rice blast disease.

\section{Applicable industries}

Agriculture and Horticulture

\section{Acknowledgement}

The authors would like to thank the Department of Biotechnology, Ramaiah Institute of Technology, Bangalore and Department of Plant biotechnology, University of Agricultural Sciences, GKVK, Bangalore for their immense support and encouragement shown throughout the completion of this research work.

\section{Ethical approval}

This article does not contain any studies with human participants or animals performed by any of the authors. 
Scire Science Multidisciplinary Journal, 1(1), 15-26 (2017)

Research Article

Path towards genetic diversity analysis and evaluation of blast resistant genes in popular varieties of paddy

Sanjana et al.

\section{References}

1. Akkaya MS and Bal BEB (2004), Assessment of genetic variation of bread wheat varieties using microsatellite markers, Euphytica 135: pp. 179-185.

2. Ashikawa I, Hayashi N, Yamane H, Kanamori H, Wu J, Matsumoto T, Ono K and Yano M (2008), Two adjacent nucleotide-binding site-leucine-rich repeat class genes are required to confer Pikm-specific rice blast resistance, Genetics 180: pp. 2267- 2276.

3. Bryan GT, Wu KS, Farrall L, Jia YL, Hershey HP, Mc-Adams SA, Faulk KN, Donaldson

GK, Tarchini R and Valent B (2000), A single amino acid difference distinguishes resistant and susceptible alleles of the rice blast resistance gene Pi-ta, Plant Cell 12: pp. 2033-2045.

4. DeWoody JA, Honeycutt RL and Skow LC (1995), Microsatellite markers in White tailed deer, J. Hered. 86: pp. 317-319.

5. Li G, Hu W, Jin R, Tan G, Zhu L and He G (2007), Simple sequence repeat analysis of interspecific hybrids and MAAL of Oryza officinaalis and Oryza sativa, Genetica 34: pp. 169180.

6. Prabakaran A, Paramasivam K, Rajesh T and Rajarajan D (2010), Molecular characterization of rice land races using SSR markers, Electron. J. Plant Breed. 1(4): pp. 512-516.

7. Rabey HE, Salem KF and Mattar MZ (2013), Genetic diversity and relatedness of eight rice (Oryza sativa L.) cultivars as revealed by AFLP and SSRs markers, Life Sci. J. 10 (1): pp. 14711479 .

8. Rajendrakumar P, Biswal AK, Sakthivel K, Madhav MS, Neeraja C, Balachandran SM, Srinivasarao K, Natarajkumar P, Hari Y, Sujatha K and Sundaram RM (2009), Development and validation of class I SSR markers targeting (GATA) $n$ repeat motifs in rice, Euphytica pp. 1-9.

9. Upadhyay P, Singh VK and Neeraja CN (2011), Identification of genotype specific alleles and molecular diversity assessment of popular rice (Oryza sativa L.) varieties of India, Int. J. Plant Breed. Genet. 5(2): pp. 130-140.

(c) (7)

This work is licensed under a Creative Commons Attribution 4.0 International License. Proper citation of this article is mandatotory wherever it is required. 